\title{
Attitudes of Primary Health Care (PHC) Gatekeepers Towards Patient Referral Policy, Machakos County, Kenya
}

\author{
Desire Aime Nshimirimana ${ }^{1, ~}$, Wanja Mwaura-Tenambergen ${ }^{1}$, Donald Kokonya ${ }^{2}$, Maureen Adoyo ${ }^{1}$ \\ ${ }^{1}$ Department of Health Systems Management, School of Medicine \& Health Sciences, Kenya Methodist University, Nairobi, Kenya \\ ${ }^{2}$ Department of Mental Health, School of Medicine, Masinde Muliro University of Science \& Technology, Kakamega, Kenya
}

Email address:

nshima2007@yahoo.fr (D. A. Nshimirimana),wanja.tenambergen@gmail.com (W. Mwaura-Tenambergen), dkokonya@yahoo.com (D. Kokonya),maureenadoyo.kemu@gmail.com (M. Adoyo)

${ }^{*}$ Corresponding author

\section{To cite this article:}

Desire Aime Nshimirimana, WanjaMwaura-Tenambergen, Donald Kokonya, Maureen Adoyo. Attitudes of Primary Health Care (PHC) Gatekeepers Towards Patient Referral Policy, Machakos County, Kenya. Science Journal of Public Health. Vol. 4, No. 4, 2016 , pp. $284-288$. doi: $10.11648 /$ j.sjph.20160404.13

Received: May 16, 2016; Accepted: May 28, 2016; Published: June 13, 2016

\begin{abstract}
Primary Health Care (PHC) serves as the foundation for building a working healthcare system that provide good health outcomes. The quality of PHC delivery and the decision to refer patients depends on some behavioural factors (knowledge, skills and behaviour) of primary care providers. The study was conducted at 100 PHC centres sampled using Taro Yamane formula, in Machakos County, Kenya, from March to May 2015. It involved 8 gender-based focus group discussions (FGDs) with patients and their caretakers. Qualitative and quantitative data were collected from emancipated children and adults aged 15-65 years excluding the disabled due to data integrity issues. The Statistical Package for Social Science (SPSS) version 20.0 and Atlas.ti 7 software were used for analysis. A questionnaire return rate of $83 \%$ was achieved of whom $84.3 \%$ were nurses $(\mathrm{p}<0.001)$ and $15.7 \%$ were diploma holders in clinical medicine (clinical officers). The health workers were young $(\mathrm{P}<0.001)$ and married $(\mathrm{p}<0.001)$. About $62 \%$ of the respondents reported to know about PHC gatekeeper system and $38 \%$ don't know about PHC gatekeeper system. The gate keepers at a majority rate $86.7 \%$ reported to have participated in workshops of which at least $40.3 \%$ participated in at least one workshop per year, means that the majority of gatekeepers don't fill the required continuing professional development (CPD) to renew their licenses. Bad behavior, poor communication, don't care attitude, long waiting time and no courtesy were mentioned by patients by $60 \%$ of respondents as the main contributing factors to non-compliance of patients with the national patient referral policy. Attitudes (knowledge, skills and behaviour) are crucial in primary care gatekeeper policy implementation. It has been made clear that nurses acquire enough knowledge from college to take care of patients but still need more practical knowledge and experience to increase their performance. This study recommends an innovative plan using incentive driven model and performance rewards in the implementation process.
\end{abstract}

Keywords: Gatekeeper, Primary Health Care, Knowledge, Behaviour, Skills, Referral

\section{Background}

Primary Health Care (PHC) is the foundation for building a working healthcare system that leads to good health outcomes [1]. It is envisaged as 'the first level of contact for individuals, families and communities with the national health system, bringing health care as close as possible to where people live and work, constituting the first element of a continuing health care process [2]. In the Kenyan health system, represented by Machakos County, a large number of patients seek hospital services (Tier 3) directly; sidestepping services offered at the PHC (Tier 2) health services, hence weakening the efficiency and cost-effective management of health services at all levels [3]. Where gatekeeper system exists, unless in emergency situations, the gatekeeper generally must pre-authorize referrals of patients to hospitals after conducting assessment of the patient's health needs [4]. The quality of PHC services delivery and the decision to refer patients depends on some behavioural factors (knowledge, skills and behaviour) of the 
PHC services providers [5]. The contributions of these factors play a big role in influencing the decision to treat or refer a patient to the higher level of the health system $[1,6]$. The knowledge of health care providers for example, is imparted at medical schools and this provides intellectual package to be translated into practice for the effective management of patients [6]. An additional knowledge on gate keeping system is crucial to understand how it can be used to cut the costs of patients care to increase efficiency [7]. The concept of gate keeping started in the late 1970s to define individuals with a high degree of knowledge from which others would seek for mentorship. The differences between the primary gatekeeper and secondary health services provider is the high degree of connectivity to the information sources by the gate keeper outside their organizations. The knowledge of gate keeping is a key asset for competing health institutions; consequently, education on gatekeeping is an important undertaking [8]. Health workers acting as gatekeepers through creating platforms of knowledge sharing can fulfill many functions at a time [9]. As gatekeepers expand their networks of interactions, they can access valuable knowledge from their networks and bring it into the operation of their daily formal way of treating patients [10]. In fact, the level of knowledge of gatekeepers functions as facilitators to access the complementary knowledge and services [11]. Studies have identified one of the main characteristics of the knowledge of a gatekeeper being that they possess a high level of social capital followed by a networks' centrality [12]. It is useful to educate medical staff about the financial consequences of their decisions [13]. Skills in the medical field are acquired and transmitted in the form of health service delivery [14]. In the patient referral system, skills are crucial in deciding whether to refer to higher or lower levels of the heath system or decide to manage patient [15].Nurses should be equipped with extra skills in order to manage complex medical conditions in order to facilitate the patient assessment process[16]. There is little research on what additional skills and competencies nurses should acquire to enhance their performance effectively [17]. It is important for nurses undertake continuing professional development (CPD) to update their knowledge and skills in order to deliver safe and effective health care [18]. Attitude in medical practice plays a big role in patient management. Don't care attitude and poor communication which results from bad attitude can contribute to patients bypassing the health facility to seek health care elsewhere [19]. Accountability in the health sector is a PHC pre-requisite for clinicians and the health systems within which they operate [20]. These clinicians and their systems are answerable to their patients and communities for addressing all of their personal health needs through a sustainable partnership with patients in the context of a family, community and the quality of PHC, patient satisfaction, efficient use of resources and ethical behavior [21].

These attitudes may depend on the personal behavior or the lack of incentives for the PHC gatekeepers. Integrated system of PHC and gate keeping system at Tier 2 is crucial in reducing unnecessary visits to hospitals for ailments which can be treated at the PHC level, thus, effectiveness, quality and overall efficiency of health care services [22]. This study aimed at determining the behavioural aspects of PHC providers that influence gate keeping role towards rationale use of resources at PHC level (Tier 2) at the County level, Kenya.

\section{Methods}

This was a convergent parallel mixed methods study design that employed both qualitative and quantitative data collection techniques in a single study [23]. The study was conducted over a 3-month period (January to March 2015). The population of interest were gatekeepers at the PHC level (managers of Health Centres and dispensaries) purposively sampled and patients at Tier 3 (Hospitals) in the public health facilities within Machakos County, Kenya, both core populations sampled purposively and the decision makers at the County level including the Chief Health Officer, the Director of Preventive Health and PHC and the Medical Superintendents of the secondary level health facilities. The Machakos County Government, with a catchment population of 150,041 [24], has 99 dispensaries, 22 health centers and 4 sub-county hospitals at Tier 3 and one county referral hospital. This means that there are 99 in charges of the dispensaries and 22 in charges of Health Centers.Using the Taro Yamane formula (1973), a minimum population sample size was calculated at 93 health managers, adjusted and rounded off to 100 to cater for an estimated 5\% non-response rate. A maximum of 12 patients constituted a focus group for discussion (FGD) as per the standard guidelines. For each hospital, 2 FGDs (by gender and age among patients and their care-takers) were conducted. The researcher administered the questions and a trained assistant recorded the proceedings and the responses during the FGDs. Primary data was captured by administering key informant interviews (KIIs) and open-ended questions (health mangers) and focus group discussions (patients and caretakers). Responses from KIIs were captured on notebooks instantly.At each subcounty hospital, 2 FGDs were conducted (males and females) among patients and their caretakers were conducted. All the study participants who had voluntarily signed their consent forms participated in this study, and all adult participants aged 18-65 years and emancipated children. The emancipated children were aged 15 years and above and fully responsible for the patients they had been accompanying to the health facilities, thereby qualifying to participate in this study. The caretakers of the patients also participated in this study along similar arguments. All qualified persons who had not voluntarily signed their consent forms; children below 15 years of age and adults above 65 years of age were excluded from this study. The study excluded the physically ill and mentally disordered patients for purposes of data integrity. Other exclusions were patients brought in as emergency cases and very sick patients. Complete data was double 
entered using Epi data, to minimize errors, there after exported to SPSS version 20.0 for analysis. Analysis involved mainly descriptive statistics while qualitative data was transferred to the Atlas.ti 7 software for analysis. Multimethods and triangulation were used in the development and management of data to enhance data accuracy, repeatability, replicability and generalizability. The study protocol was reviewed and approved by the scientific committee of the Kenya Methodist University Institutional Research and Ethics Committee in May 2015.

\section{Findings}

\subsection{Socio-Demographic Characteristics $(n=83)$}

Out of the 100 questionnaires administered to the study participants, 83 responses were received, giving a response rate of $83 \%$. Of the 83 valid responses, a large majority $(84.3 \%)$ of them were nurses and $15.7 \%$ were diploma medicine practitioners (clinical officers). This staff deployment pattern was in tandem with known proportion of nurses to clinical officers in Kenya. The results were also a true reflection of the dominance of the nursing health managers at PHC facilities in Kenya. This study used a statistical test (Chi-square) at $95 \%$ confidence interval with a $5 \%$ margin of error. The variables were statistically significant at $\mathrm{p}$-value of 0.05 or less.

Table 1. Socio-demographic characteristics $(n=83)$.

\begin{tabular}{|c|c|c|c|c|}
\hline Characteristics & Categories & Frequency & $\%$ & P-value \\
\hline \multirow{2}{*}{$\begin{array}{l}\text { Designation of the } \\
\text { health worker }\end{array}$} & Nurse & 70 & 84.3 & \multirow{2}{*}{$<.001$} \\
\hline & Clinical officer & 13 & 15.7 & \\
\hline \multirow{2}{*}{ Gender } & Female & 49 & 59.0 & \multirow{2}{*}{124} \\
\hline & Male & 34 & 41.0 & \\
\hline \multirow{4}{*}{ Age } & $18-25$ & 6 & 7.2 & \multirow{4}{*}{$<.001$} \\
\hline & $26-35$ & 33 & 39.8 & \\
\hline & $36-45$ & 28 & 33.7 & \\
\hline & $46+$ & 16 & 19.3 & \\
\hline \multirow{2}{*}{ Marital status } & Married & 67 & 80.7 & \multirow{2}{*}{$<.001$} \\
\hline & Single & 16 & 19.3 & \\
\hline
\end{tabular}

Though there were more female $(59 \%)$ gatekeepers than males $(41 \%)$, the gender difference did not have significant $(0.124)$ weight on gate keeping. A predominantly young and energetic aged $26-45$ years significantly $(\mathrm{p}<0.01)$ dominated (73.\%\%) gate keeping in Machakos County, Kenya, as opposed to inexperience $(7.2 \%)$ below 25 years of age and experience $(19.3 \%)$ above 46 years of age. This implies that the Tier 2 level of health care in Machakos County needs experience to boost the institutional memory. The management of gate keeping system was by and large $(p<0.001)$ in the hands of married $(80.7 \%)$ health care providers compared to the single (19.3\%) (Table 1).

\subsection{Knowledge of PHC Providers on Gate Keeping System}

About 51(62\%) of the respondents reported to know about PHC gatekeeper system and 32(38\%) didn't know about PHC gatekeeper system. Having knowledge about the gatekeeper system was found to be the first necessary step in gatekeeper policy implementation. This implied that to train health managers on the gatekeeper system could be an easy exercise if the Machakos County opted for the PHC gatekeeper system.

\subsection{Skills of PHC Providers on Gatekeeper System}

The gate keepers (health managers) at a majority rate $72(86.7 \%)$ reported to have participated in workshops/seminars of which at least 33(40.3\%) participated in at least one seminar/workshop per year. This means that the minimum continuing professional development (CPD) required by the regular bodies for health personnel to renew their licenses was not met for some staffs.

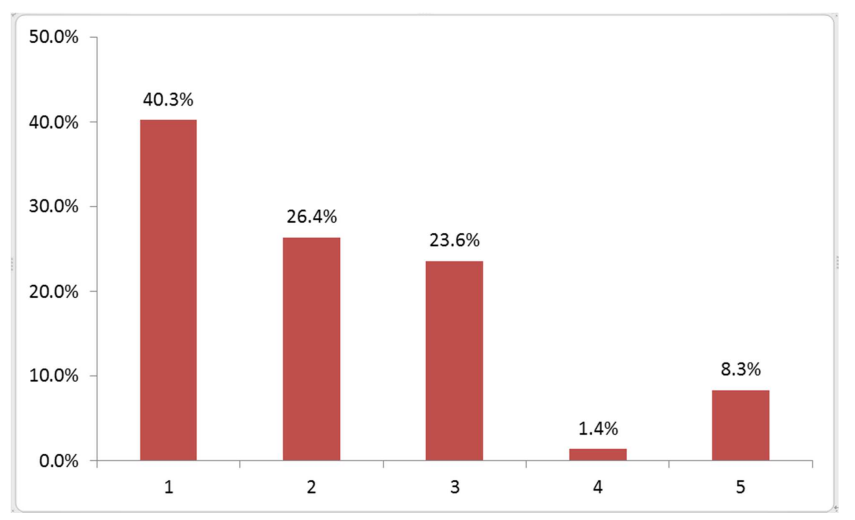

Figure 1. Average Number of Seminars/Workshops Attended/Year (n=83).

With regard to the skills development of gate keepers at the PHC level, there was a progressive decline in knowledgeseeking behaviour among the gatekeepers, with two-thirds $55(66.4 \%)$ attending up to two workshops (CPDs) and only a quarter $21(25 \%)$ attending three (3) and or four workshops per year, a finding not consistent with the large and young employees in Machakos County and the need for new knowledge to cope with changing medical practice and emerging and re-emerging diseases worldwide. Overall, over four-fifths $(86.7 \%)$ had attended at least 3 out of 5 workshops and or seminars. In terms of the skills of health workers at the PHC level, participants in FGDs commented on three categories of skills: similarity, acquired and enough skills. They believed that nurses at the PHC level had similar skills as those at hospitals and that the skills they possessed were sufficient to provide good health care services.

\subsection{Behaviour of Primary Care Providers on Referral Decision to the Higher Level of Health Care}

Bad behavior, poor communication, don't care attitude, long waiting time and no courtesy were mentioned by patients by $60 \%$ of respondents as the main contributing factors to non-compliance of patients with the National Patient Referral Policy of Kenya. Poor communication between health care workers and patients was the first concern of patients. Some gatekeepers at the PHC were reported to have little or no courtesy and they exuded bad behavior towards their patients. Some were reported to have 
espoused don't care attitudes resulting in long waiting hours that were discouraging to the patients. The patients also concurred that not all the gatekeepers at PHC centres were bad, and that some had good public manners. Good behavior of the health workers at the PHC level was crucial to the better management and effective patient referral system in Kenya. This had a big impact in deciding whether a patient was to be treated at the PHC level or to be referred to the hospital. Health workers with bad behaviors were reported to send away patients who were willing to be treated at their PHC facilities and the patients' wish to consult at the PHC level was dependent on good customer relationship. These attitudes may depend on personal behavior, or could also depend on the lack of incentives for the PHC gatekeepers.

\section{Discussion}

Health managers at the PHC level had key roles in the care of patients. They (gatekeepers) were the ones to decide whether to treat or refer patients. In this case, it was important for them to be equipped with the knowledge on gatekeeper system and be aware of their roles and responsibilities in cutting the costs of health care (efficiency) in the Kenyan health system. Skills are acquired and transmitted in form of health service delivery in medical field. In health referral system, practical skills are key in deciding for a referral or managing a patient. The production and distribution of knowledge is not evenly distributed, but channeled through different channels. The findings of this study are similar to those of Mosadeghrad in 2014. The most significant sociodemographic factors in gate keeping at the PHC level in Machakos County, Kenya were the designation of the health workers $(p<0.001)$, young in age and by extension inexperienced $(p<001)$ and being married $(p<0.001)$. These factors were found to be associated with patients bypassing the PHC centres (Tier 2) to seek preventive and promotive health care services at hospitals (Tier 3). However, the County system of health care in Kenya commenced in the year 2013 and most of the counties are in process of implementation, which is likely to have contributed to a large movement of health personnel that in turn could account for the youthful and inexperienced managers. These arguments were backed by the large number $(38 \%)$ of health workers who had no idea about gatekeeper system in the PHC settings in Kenya. These findings were made against a backdrop of a high (86.7\%) attendance at workshops and seminars of at least $3 / 5$ per year that did not demonstrate training or appraisal on the gatekeeper system. The findings of this study were similar to those by Lundvall and Nielsen, which stipulated that knowledge was a key asset for competing firms and consequently, that learning was a key process. At the same time production and distribution of the knowledge was viewed as socially embedded [25]. This study established that health care workers did not treat patients well to their satisfaction, resulting in loss of trust in the PHC facilities. In the study done in 2000, in the Israelite health care system, the author advised that policy implementation be done gradually and considers incentive driven model rather than regulations when implementing primary gatekeeper system [26]. In Egypt in 2010, when implementing the gatekeeper system to strengthen PHC, decision makers applied penalties for self referrals to hospitals [27]. The Israelite and Egyptian methodology were contradictory.

\section{Conclusion}

Attitudes (knowledge, skills and behaviour) are crucial in primary care gatekeeper policy implementation. It has been made clear that nurses acquire enough knowledge from college to take care of patients but still need more practical knowledge and experience to increase their performance. On top of knowledge, they also need to attend workshops, seminars and scientific conferences to gain practical skills as well as CPDs according to the nursing council which normally require some CPDs to renew their licenses. Nevertheless, the behaviour of gatekeepers raises challenges in patient management as patients accuse them to be with no courtesy and don't care attitude. This study recommends an innovative plan using incentive driven model and performance rewards in the implementation process. This study recommends that health workers as they increase their professional skill, they should also acquire the skills related to rationalization of the limited resources provided by the national level. On top of this, nurses, who are the majority at the PHC level need to be trained on the gatekeeper system to acquire skills to fill in their gaps in the management of the referral system of patients, being conscious of their roles and responsibilities in the cutting costs of unnecessary consultations at hospital level. Different types of incentives (financial, trainings, equipment) can motivate primary care workers to provide health services to patients who would have been referred to higher level and therefore right decision either to refer or treat a patient.

\section{Acknowledgements}

I sincerely acknowledge the research assistant (Raphael Mutiso) and the biostatistician (Elijah Kipkech Kipchumba) for contributing to data collection and analysis.

\section{References}

[1] Shi L. Impact of Primary Care. A focused review. Hindawi Publishing Corporation Scientifica 2012.DOI: http://dx.doi.org/10.6064/2012/432892. Retrieved October, 5th, 2014.

[2] Hsieh C-R. V, Wu C-L. J, Wu N.T and Chiang L T. Universal Coverage for Primary Health Care Is a Wise Investment. Evidence From 102 Low-and Middle-Income Countries. Asian Journal of Public Health 2013. Taiwan.

[3] Ministry of Health. The State of the Health Referral System in Kenya: Results from a Baseline Study on the Functionality of the Health Referral System in Eight Counties. USAID and MEASURE Evaluation PIMA 2013. Nairobi, Kenya. 
[4] Kluge E-H W. Comparing Healthcare Systems: Outcomes, Ethical Principles, and Social Values. Medscape General Medicine 2007, 9(4), 29.

[5] Mosadeghrad AM. Factors influencing healthcare service quality. Int J Health Policy Manag 2014; 3: 77-89.doi: 10.15171/ijhpm.2014.65.

[6] Kebriaei A and Akbari F. Quality Gap of Primary Health Care Services at Kashan District Health Centers, Iran. J. Med. Sci.2006, 6(3): 393-399.

[7] Fachinelli C A, Macke J, Rickenberg J and Fachinelli L. A social approach for the concept of knowledge gatekeepers: the case of the american community colleges. Brazilan Journal of Management \& Innovation 2013 v.1, n.1.

[8] Lazaric N, Longhi Cand Thomas C. Gatekeepers of Knowledge Versus Platforms of Knowledge: From Potential to Realized Absorptive Capacity. Regional Studies 2008, Vol. 00.00, pp. 1-16.

[9] Institute of Medicine (US) Roundtable on Evidence-Based Medicine. Olsen LA, AisnerD, McGinnis JM, editors. The Learning Healthcare System: Workshop Summary. Washington (DC): National Academies Press (US) 2007 , Training the Learning Health Professional. Available from: http://www.ncbi.nlm.nih.gov/books/NBK53499/.

[10] Berger B. Employee/Organizational Communications. Institute of Public relations. The Science Beneath the Art of Public Relations 2007. Retrieved from internet http://www.instituteforpr.org/employee-organizationalcommunications/.

[11] Petruzzelli M. A. Proximity and knowledge gatekeepers: the case of the Polytechnic University of Turin", Journal of Knowledge Management 2008, Vol. 12 Iss: 5, pp.34-51. http://dx.doi.org/10.1108/13673270810902920.

[12] Petruzzelli M. A, Albino V, Carbonara N, Rotolo D. Leveraging learning behavior and network structure to improve knowledge gatekeeper' performance", Journal of Knowledge Management 2010, Vol. 14 Iss: 5, pp.635-658. Http://dx.doi.org/10.1108/13673271011074818.

[13] Yigitcanlar $\mathrm{T} \&$ Fachinelli $\mathrm{C}$ A. The 4th knowledge cities. World summit. The world capital institute \& Ibero-American community for knowledge systems present. Brazil 2011. Retrieved from http://eprints.qut.edu.au on $5^{\text {th }}$ December 2014.

[14] Coiera E. Communication Systems in Healthcare. Clin Biochem Rev 2006 Vol 27. Centre for Health Informatics, University of New South Wales, NSW 2052, Australia

[15] Rivers A and Pand Glover H. S. Health care competition, strategic mission, and patient satisfaction: research model and propositions. J Health Organ Manag. 2013; 22(6): 627-641.
[16] Mitchell HP. Patient Safety and Quality. An Evidence-Based Handbook for Nurses 2008. Retrieved on internet http:/www.ncbi.nlm.nih.gov/books/NBK2681/.

[17] Cathy W. Assessing Leadership in Nurse Practitioner Candidates. Australian Journal of Advanced Nursing 2008, vol.26, No.1:67-76.

[18] Ross K., Barr J. and Stevens J. Mandatory continuing professional development requirements: what does this mean for Australian nurses. BMC Nursing 2013 12:9. doi: $10.1186 / 1472-6955-12-9$.

[19] Mannava P, Durrant K., Fisher J, Chersich M. and Luchters S. Attitudes and behaviours of maternal health care providers in interactions with clients: a systematic review. Globalization and Health. 2015 11:36 DOI 10.1186/s12992-015-0117-9.

[20] World Health Organization. Everybody's Business: Strengthening Health Systems to improve Health Outcomes: WHO's Framework for Action. WHO Document Production Services 2007, Geneva, Switzerland.

[21] Simou E, Karamagioli E and Rmeliotou A. Reinventing primary health care in the Greece of austerity: the role of health-care workers. Primary Health Care Research and Development. Cambridge University Press 2013. Athens, Greece. Retrieved from http://journals.cambridge.orgon $17^{\text {th }}$ November 2014.

[22] Schlette S, Lisac M and Blum K. Integrated primary care in Germany: the road ahead. International Journal of Integrated Care-Vol. 9, 20 April 2009 - ISSN 1568-4156. Retrieved on internet: http://www.ijic.org/.

[23] Johnson B. and Onwuegbuzie J. A. Mixed Methods Research: A Research Paradigm Whose Time Has Come.

[24] The 2009 Kenya Population and Housing Census. Counting Our People for the Implementation of Vision 2030.Ministry of State for Planning, National Development and Vision 2030.Kenya National Bureau of Statistics 2010 vol IC. Nairobi, Kenya.

[25] Lundvall BA and Nielsen P. Knowledge management and innovation performance. International Journal of Manpower 2007, Vol. 28 Iss: 3/4, pp.207-223. doi: http://dx.doi.org/10.1108/01437720710755218.

[26] Tabenkin $\mathrm{H}$ and Gross $\mathrm{R}$. The role of the primary care physician in the Israeli health care system as a 'gatekeeper' the viewpoint of health care policy makers. Health Policy 2000Volume 52, Issue 2, Pages 7385.doi:http://dx.doi.org/10.1016/S0168-8510(00)00070.

[27] Ward R Implementing a gatekeeper system to strengthen primary care in Egypt: Pilot Study. Medical School, Australian National University, Canberra, Australia. Eastern Mediterranean Health Journal 2010. Vol 16 No 6. 